\title{
INSIDIOUS THROMBOSIS OF THE ABDOMINAL AORTA
}

\author{
BY \\ J. F. GOODWIN AND E. PETRIE \\ From the Postgraduate Medical School of London \\ Received August 15, 1950
}

The clinical manifestations of embolic occlusion of the bifurcation of the abdominal aorta are sufficiently well recognized and of too frequent occurrence to require enumeration. Cases previously reported have usually been described under the title of "embolism and thrombosis of the abdominal aorta." In other reports entitled "thrombosis of the abdominal aorta," the descriptions indicate prior embolization, the thrombotic process occurring secondarily to lodgement of a saddle embolus, or developing in a retrograde manner following embolic occlusion of an iliac or femoral artery. The syndrome of massive embolization of the abdominal aorta is a dramatic and sudden event demanding prompt diagnosis and therapy if life and limbs are to be preserved. It is not likely to be overlooked.

In contrast, it is not generally recognized that insidious thrombosis of the terminal aorta, not dependent upon prior embolization, may occur. It is probable that the incidence of this condition is greater than the number of published cases would suggest. Elken and Cooper (1949) record that ten examples were encountered by them over the course of twenty months.

The first description of aortic thrombosis is that of Barth, who in 1948 recorded the finding at necropsy of partial occlusion of the abdominal aorta in a woman who died from phthisis. During life there had been no symptoms referable to this lesion. Welch's reference to the problem, as seen by the morbid anatomist, is pertinent. He stated "it is difficult, indeed impossible, from published descriptions . . : to determine accurately how many of these cases were referable to embolism and how many to thrombosis." Since 1940 the clinical picture of insidious thrombosis of the terminal aorta has been made clear, largely owing to the communications of Leriche and his associates (1948).

Symptomatology. Of the published case reports of insidious thrombosis of the abdominal aorta, all indubitable examples have been male subjects. The age at the onset of symptoms has ranged from 28 to 62 years. At the time of the initial diagnosis, the subject has usually been in his fifth or sixth decade. The duration of symptoms before a diagnosis was arrived at has varied from 15 months to 15 years, this latter extreme duration in a patient who had already developed gangrene of one leg.

Leriche has emphasized that the diagnosis can, and should, be made at a relatively early stage when significant trophic changes have not yet occurred. At this stage appropriate treatment can avert or delay the onset of incapacitating ischæmic lesions in the lower limbs. He states that in this early phase of the disease, patients present with one or other of the following features:

(1) the inability to maintain a stable erection,

(2) extreme fatiguability of the lower limbs when walking or standing,

(3) a generalized atrophy of muscle in both buttocks and in both lower limbs, and

(4) a marked pallor of the lower limbs.

The details of 24 cases that we consider to be examples of insidious thrombosis of the aorta are reported in Table I (p. 556).

The case recorded below is of interest since the presenting symptoms were referable to a severe hypertensive state. The peripheral circulatory changes in the lower limbs were incidental findings. 


\section{CASE REPORT}

History. The patient was a married man aged 49 years, whose occupation was truck driving. In his youth he had been a boxer, and had remained perfectly fit until three months prior to admission to hospital. About this time he began to have severe bilateral frontal headaches which tended to radiate to the occiput. They usually came on during the early evening on returning from work, and they tended to keep him awake at night. The more severe attacks were associated with bouts of nausea and occasional vomiting. There was no past history of trauma or renal disease, and no family history of hypertension.

Physical examination. The patient appeared younger than his years. The trunk and upper extremities were well developed and muscular, in contrast to the buttocks and lower limbs which appeared to be lacking in muscle mass.

Cardiovascular system. Pulse regular, 80 beats a minute. The heart was not enlarged. There were no abnormal pulsations at the root of the neck. At the apex there was a presystolic triple rhythm and a soft systolic murmur. The aortic second sound was accentuated. The blood pressure was 210/110 in both arms, and by oscillometry was estimated at $140 / 80$ in the thighs. The femoral pulses were just palpable on admission but later disappeared. The popliteal and ankle pulses were impalpable. There was no clinical evidence of any collateral circulation except a slight pulsation in the third right interspace which was thought to be due to a dilated internal mammary artery.

Except for the muscle wasting, previously mentioned, there were no trophic changes in the lower limbs, but the feet were persistently cold, rather pale and showed delayed reactive hyperæmia. The optic fundi showed small circular hæmorrhages and patches of recent exudate. The right disc was swollen and slightly œdematous. The other systems were normal. Mensuration: height, $159 \frac{1}{2} \mathrm{~cm}$.; span, $161 \frac{1}{2} \mathrm{~cm}$.; height to pubis, $77 \frac{1}{2} \mathrm{~cm}$.

Investigations. Radiography: Slight left ventricular enlargement. Normal aortic knuckle. No rib notching. Patchy calcification of the wall of the abdominal aorta was present. Urine: trace of albumen, occasional red and epithelial cells only, seen on repeated examination. Blood urea: $29 \mathrm{mg}$. per $100 \mathrm{ml}$. Pyelography: normal excretion; no abnormality other than a double ureter on the right side.

Renal clearances. (Average of 2 estimations.)

Glomerular filtration rate $-54 \cdot 8 \mathrm{ml}$. per minute (normal $=131 \pm 21 \mathrm{ml}$.).

Effective renal plasma flow-382 ml. , " ,,$\quad=697 \pm 136 \mathrm{ml}$.$) .$

Filtration fraction $\quad-14 \% \quad, \quad, \quad, \quad,=19 \pm 2 \%)$.

Electrocardiogram. Electrically vertical heart with marked left ventricular preponderance.

Aortogram. A retrograde aortogram was performed through a cardiac catheter introduced via the radial artery into the arch of the aorta. The films exposed to demonstrate the passage of the opaque medium past the aortic arch showed this to be of normal configuration. A second series of exposures designed to visualize the abdominal aorta indicated that the dye passed along the aorta as far as the level of the 3rd lumbar vertebra where the aorta appeared to terminate in a "rat tail " constriction, but before doing so gave off right and left branches that were considered to be the renal arteries (Fig. 1).

Intra-arterial pressures: (Strain gauge manometer). Brachial B.P. 200/105, mean 139. Femoral B.P. 108/91, mean 101 .

Fluorescin circulation rate: after maximum reflex heating. (Method of Macgregor and Wayne, 1950). Right foot minus L. arm time: 15 sec., i.e. arm to foot time minus arm to arm time (R).

Left foot minus L. arm time: 15 sec., i.e. arm to foot time minus arm to arm time (L). (normal range: 8-13 seconds).
Limb blood flows: (i) Before heating Feet: $2.6 \mathrm{ml} .\left(100 \mathrm{ml}\right.$. tissue $\left./ \mathrm{min} . \mathrm{T}^{\circ}=24\right)$. Venous occlusion plethysmography. Hands $: 8.5 \mathrm{ml}$. ( , , , , , $\left.\mathrm{T}^{\circ}=20 \cdot 8\right)$. (ii) After heating Feet: $11 \mathrm{ml}$. ( " , , , $\left.\quad \mathrm{T}^{\circ}=34^{\circ}\right)$. Lower limit of normal range for method used. Hands: $16 \mathrm{ml}$. ( ", " " ",

Subsequent progress. The patient failed to obtain any relief from his symptoms with conservative treatment. He was referred to Mr. Peter Martin who considered that thoracolumbar sympathectomy would be advisable. This was carried out in two stages. At operation the aorta, from a point immediately below the origin of the renal arteries to beyond its bifurcation, was found to be pulseless and completely occluded by thrombus. The state of the vessel precluded any attempt at operative repair. Renal biopsies were taken which were reported by Dr. C. V. Harrison as follows.

"Both biopsies showed essentially the same histology. The kidney structure was largely normal. 


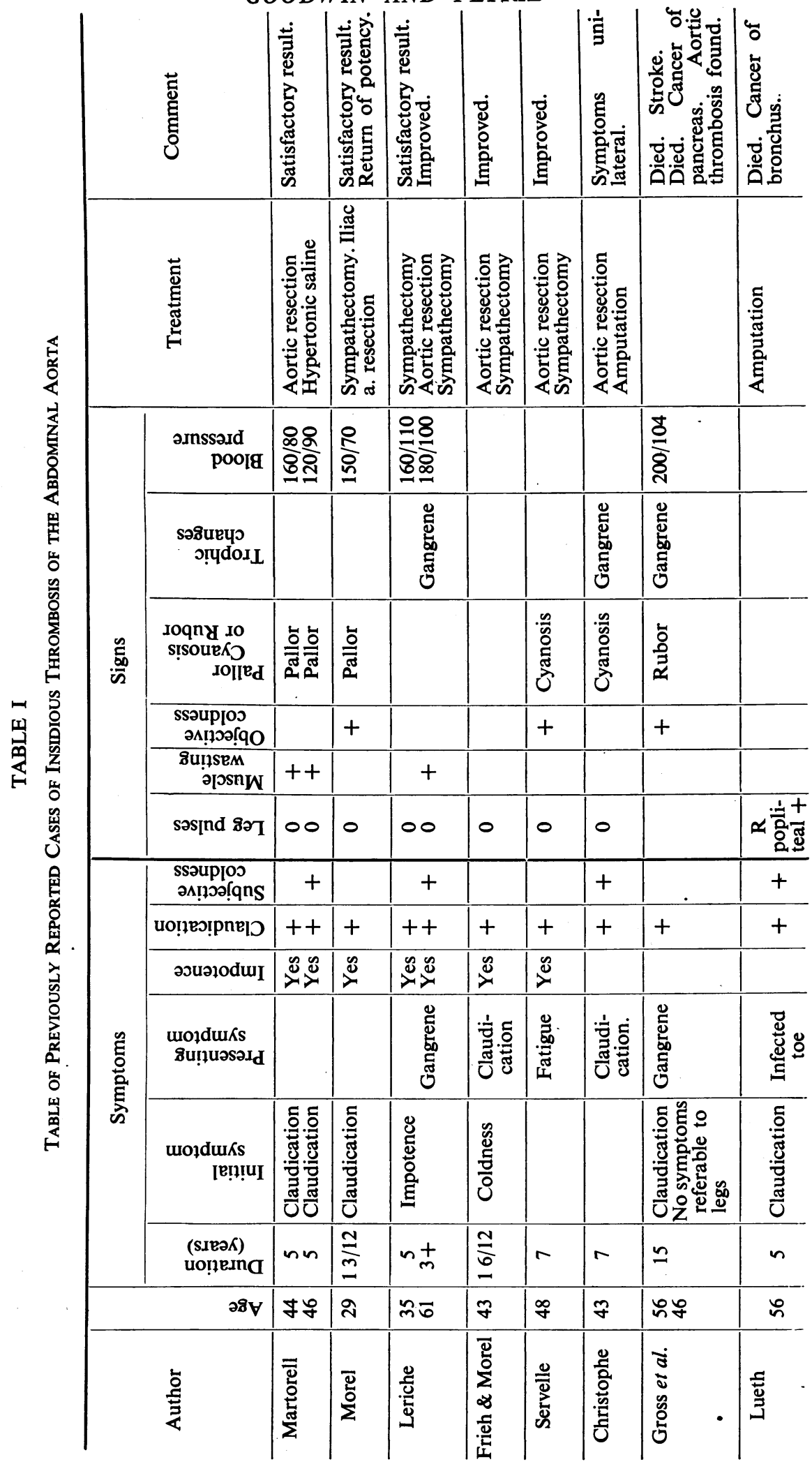




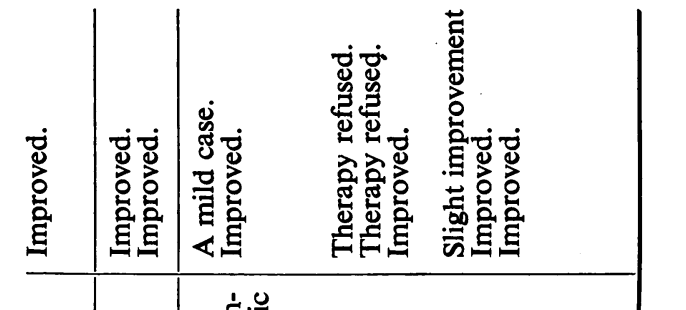

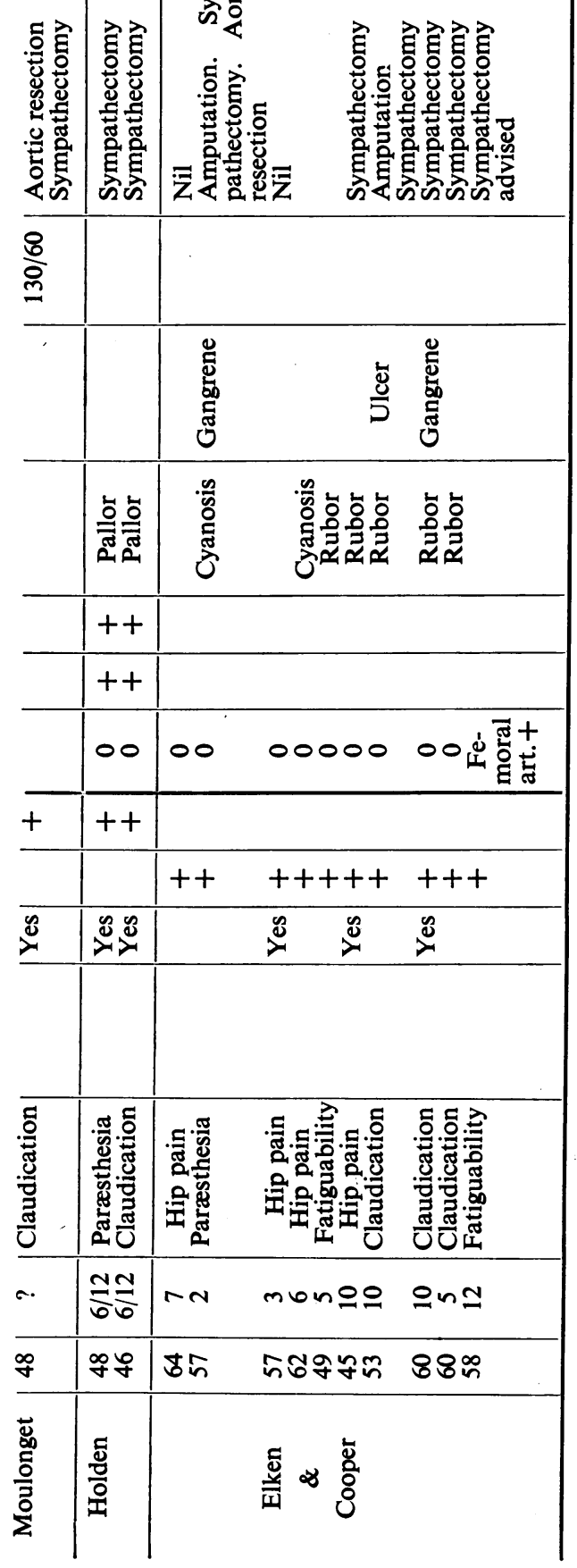



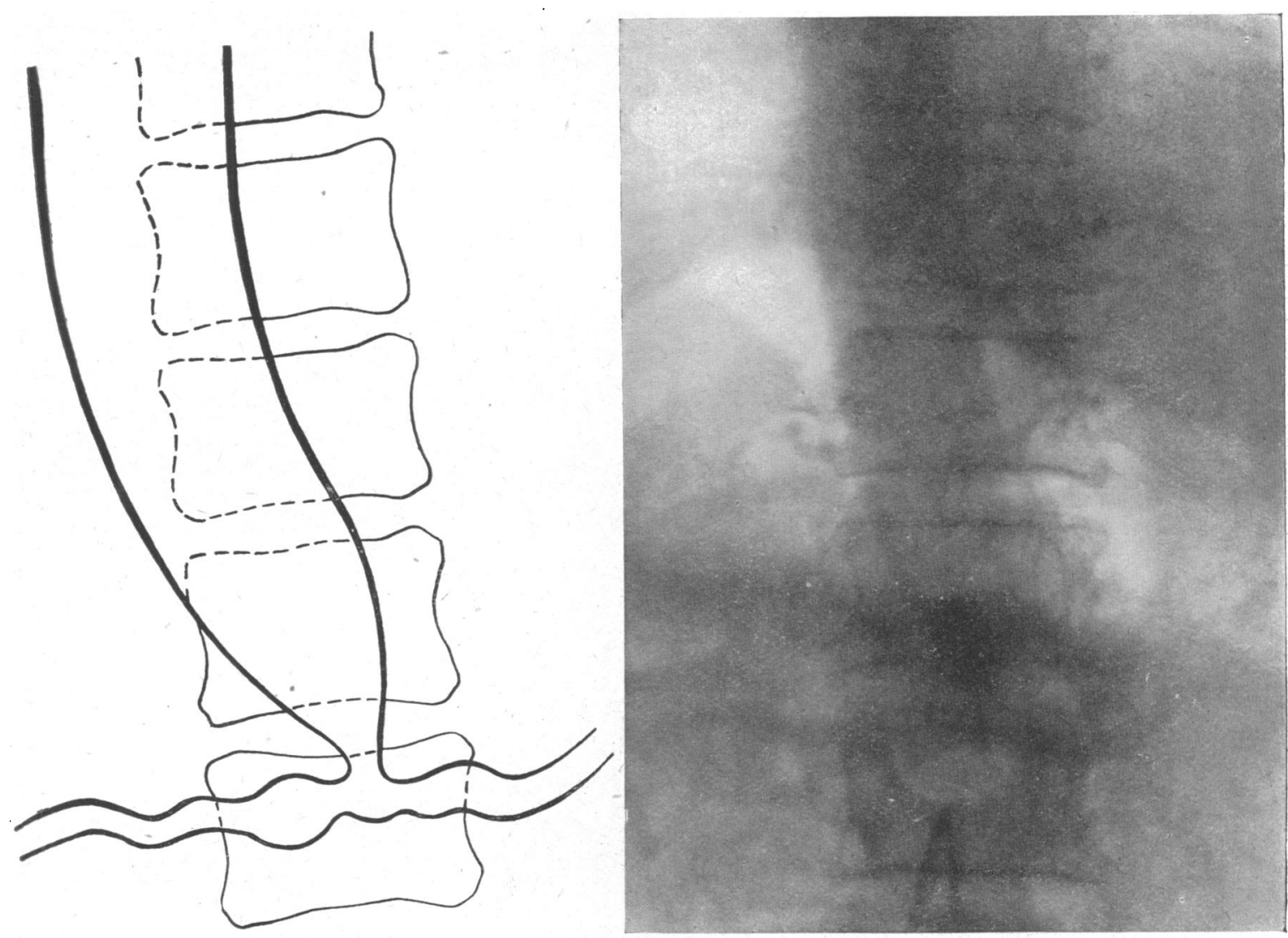

Fig. 1.-Retrograde arterial aortogram showing obliteration of the aorta at the level of the second lumbar vertebra with patent renal arteries.

There was widespread hyaline change in the afferent glomerular arterioles and in a few cases this had spread to the adjacent part of the glomerular basement membrane. A few glomeruli had undergone fibrosis and their tubules had atrophied, but the rest appeared healthy. The picture as a whole suggested a kidney which had been subjected to a severe degree of hypertension." (Fig. 2).

Post-operative progress. Immediately after operation the blood pressure fell to normal levels.

Fluorescein tests (i) After right sympathectomy.

Right foot minus arm time $=8 \mathrm{sec} .\left(\mathrm{T}^{\circ}\right.$ foot $\left.=31^{\circ}\right)$.

Left foot minus arm time $=13 \mathrm{sec}$. $\left(\mathrm{T}^{\circ}\right.$ foot $\left.=26 \cdot 8^{\circ}\right)$.

(ii) After left sympathectomy.

Right foot minus arm time $=11 \mathrm{sec}$. $\left(\mathrm{T}^{\circ}\right.$ foot $\left.=32 \cdot 9^{\circ}\right)$.

Left foot minus arm time $=12 \mathrm{sec}$. $\left(\mathrm{T}^{\circ}\right.$ foot $\left.=32 \cdot 2^{\circ}\right)$.

Further progress. Twelve weeks after operation the patient stated that he was free from headaches but complained of pain in the muscles of both thighs on walking 100 yards, relieved by resting. Both feet were cool; the pulses had not returned. There was no sweating and reactive hyperæmia was slightly delayed. Brachial blood pressure, lying: 230/130. Brachial blood pressure, standing: 170/110. Brachial blood pressure, standing, after walking 40 yards: $160 / 100$. The optic fundi showed partial resolution of the original hæmorrhages, and several new small punctate exudates.

\section{COMMENT}

Although presenting some of the typical signs of thrombosis of the terminal aorta, the case reported above is unusual in that the presenting symptoms were solely those of severe hypertension. 
This is in contrast to the finding of ischæmic symptoms referable to the lower limbs in twentythree of the twenty-four previously reported cases. Of these cases, no less than twenty had intermittent claudication and three had pain at rest. Pain in the hips on walking was noted by Elkin and Cooper in four of their patients; it was thought to be characteristic of occlusion'of the terminal aorta.

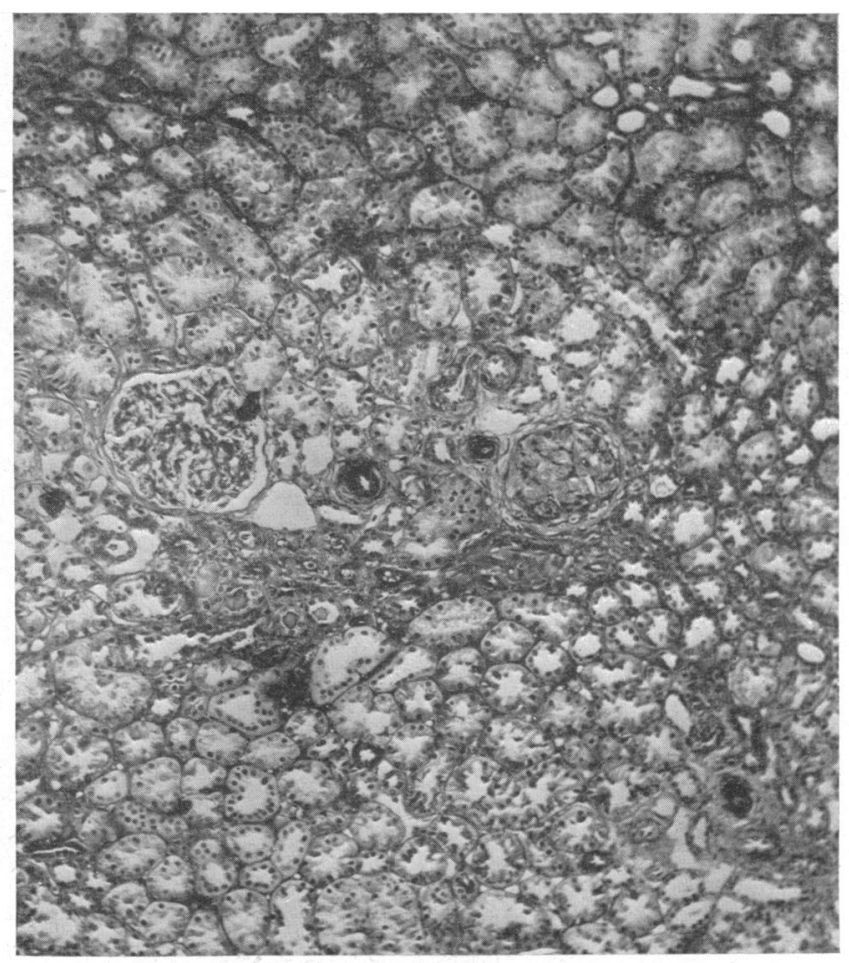

Fig. 2.-Kidney biopsy. Two arterioles near the centre show severe hyaline change. The larger glomerulus is healthy but its arteriole at the point of entry is hyaline. The smaller glomerulus and its tubules have undergone fibrosis. (Stain: Picro-Mallory, $\times 90$ ).

In the present case neither easy fatiguability of the lower limbs nor claudication occurred before operation, but after it the onset of pain in the upper part of the thighs was a conspicuous feature-a symptom that was attributed to the presence of a degree of orthostatic hypotension. It was considered that after sympathectomy, in the upright posture, the blood pressure maintaining the collateral arterial supply to the lower limbs might not be adequate to meet the demands of the active muscles.

Although apparently seldom looked for, calcification of the abdominal aorta was detected radiologically in two cases, in our case, and in one in which it was found at necropsy. The brachial blood pressure was recorded in seven cases, but was significantly raised in only two. In the few reports that included the results of oscillometry, the pulsations were absent or markedly reduced in the thighs and calves. No records of eye ground examination were available. It should be mentioned that the heart was considered to be normal in this collected series, as patients having cardiac lesions likely to predispose to embolism were automatically excluded.

In the light of the present case and of those previously reported, it would appear that certain of Leriche's criteria require modification. He emphasized that extreme fatiguability of the lower 
limbs rather than claudication occurred. Although fatiguability and parasthesia of the legs and thighs did occur frequently in the series studied, true claudication of the calf was the predominant symptom. Furthermore, Leriche considered that trophic changes were characteristically absent. However, various reports have included the finding of trophic changes of all grades up to and including advanced gangrene of the limb. There appeared to be no correlation between the duration of the disease and the presence or absence of trophic changes. For example, Elken and Cooper's second case had advanced gangrene although his symptoms were of only two years' duration. The presence of trophic changes could probably be more appropriately correlated with the rapidity of spread of the obstructive processes in the aorta than with the lapse of time.

\section{SUMMARY}

Earlier reports relating to insidious thrombosis of the abdominal aorta are reviewed, and the salient features of the twenty-five authentic cases previously described are briefly analysed.

It was found that either frank intermittent claudication of the calves or an aching in the hips and thighs on walking was an almost invariable early symptom. Mild or severe trophic changes, in the lower limbs, frequently improved by lumbar sympathectomy, were often present.

A case is reported in which thrombosis of the aorta occurred insidiously below the origin of the renal arteries. The presenting symptoms were unlike those of the cases reviewed in previously reported series in that they were entirely referable to the effects of a severe hypertensive state. The circulatory changes in the lower limbs, and particularly the muscle wasting, were important features suggesting that any obstruction in the aorta was of recent development. The results of instrumental examination of the lesion, and of its effects upon the peripheral circulation are described, as are the findings at operation.

After sympathectomy, the present case came to resemble closely many of those described in the review, in that there developed an easy fatiguability of the lower limbs, and on walking a rapidly induced aching of hips and thighs.

It is suggested that Leriche's diagnostic criteria should be extended if cases of insidious thrombosis of the aorta are not to go undiagnosed.

Our thanks are due to Dr. K. G. Lowe for renal clearance studies, to Dr. S. Kaplan and Dr. R. B. Lynn for estimation of peripheral blood flows, and to Mr. Peter Martin for undertaking the surgical care of this case.

Barth (1848). Bull. Soc. Anat., Paris, 23, 260.

Christophe, I. (1947). Acta chir. belge., 56, 8.

Elken, D. C., and Cooper, F. W. (1949). Ann. Surg., 130, 417.

Frieh, P., and Morel, A. (1946). Lyon. chir., 41, 17.

Gross, H., and Philips, B. (1940). Amer. J. med. Sci., 200, 203.

Holden, W. D. (1946). Arch. Surg., 53, 456.

Leriche, R. (1940). Pr. Méd., 48, 601.

—, and Morel, A. (1948). Ann. Surg., 127, 193.

Lueth, H. C. (1940). Ann. intern. Med., 13, 1167.

Macgregor, A. G., and Wayne, E. J. (1951). Brit. Heart J., 13, 80.

Martorell, F. (1942). Rev. clin. esp., 5, 130.

Moulonguet, P. (1945). Mem. Acad. Chir., 71, 137.

Serville, M. (1946). Mem. Acad. Chir., 72, 224.

Welch, W. H. (1899). A System of Medicine, VI, 274. 